\title{
THE INFLUENCE OF THIN NICKEL COATINGS ON THE GOSS-TEXTURE DEVELOPMENT IN IRON-3\% SILICON
}

\author{
P. GANGLI $\dagger$ and K. LÜCKE \\ Institut für Allgemeine Metallkunde und Metallphysik, RWTH Aachen, F.R.G.
}

Microstructure and texture (ODF) investigations were carried out on $\mathrm{Fe}-3 \% \mathrm{Si}$ electrical steels with different $\mathrm{C}, \mathrm{MnS}$ and AIN content (CGO and HGO quality). The main result was that by a thin $(0.25 \mu \mathrm{m})$ Ni layer on the sheet surfaces produced by electroplating before the final anneal the starting temperature of discontinuous grain growth could be decreased and the Goss texture could be sharpened. This effect was influenced by the heating rate and disappeared after decarburization. It is caused by the diffusion of $\mathrm{Ni}$ along the grain boundaries by which the segregation and precipitation characteristics of elements like $\mathrm{C}, \mathrm{N}, \mathrm{S}$, is changed.

KEY WORDS Discontinuous grain growth, Goss texture, Electroplating, Grain boundary diffusion, Segregation, $\mathrm{Fe}-3 \% \mathrm{Si}$, Nickel

The good magnetic properties of electrical steels (i.e. Fe-3\% $\mathrm{Si}$ alloys) are strongly related to the development of the Goss texture $\{011\}\langle 100\rangle$ by discontinuous grain growth (DGG). For this reason most efforts to improve the magnetic properties are connected with influencing the grain growth process. The number of reports on DGG in these alloys-referred to by many as "abnormal" grain growth-that make use of second phase, solute, and texture inhibition is voluminous (e.g.). ${ }^{1-20}$ Methods of investigation range from observing various features of microstructure, ${ }^{3,5}$ to highly sophisticated texture analyses, ${ }^{6,7}$ also including determination of individual grain orientation topography (e.g. by Selected Area Channeling Patterns) ${ }^{8}$ A number of grain growth models try to explain experimental results whereby in most cases also computer simulation is applied. ${ }^{13-20}$

While all these previous experimental efforts to influence grain growth were directed to affect bulk material, the present paper is concerned with a pure surface measure, namely studying the influence of Ni-plating on the development of the Goss texture. Although good magnetic properties of $\mathrm{Ni}$ and $\mathrm{Fe}-\mathrm{Ni}$ alloys are well known, no attempt has yet been made to combine properties of a $\mathrm{Ni}$-overlayer with those of the $\mathrm{Fe}-\mathrm{Si}$ base material except for the preliminary investigation of the present authors on Ni-coated Fe3\% $\mathrm{Si}$ which demonstrated a strong influence of the coating on the final Goss-texture. ${ }^{21}$ Of course, this "sandwiched" material ( $\mathrm{Ni} / \mathrm{Fe} 3 \% \mathrm{Si} / \mathrm{Ni})$ encorporates a complicated combination of factors only understood individually. For example, grain growth is here influenced by texture and inhibited by partially soluble $\mathrm{AIN}, \mathrm{MnS} \mathrm{S}^{31,33}$ and $\mathrm{Fe}_{3} \mathrm{C}$ second phase particles as well as by $\mathrm{C}, \mathrm{N}, \mathrm{S}$ and $\mathrm{Ni}$ segregates ${ }^{11,24}$ that are in interplay with grain boundary diffusion of nickel. ${ }^{23}$

† On leave from Technical University of Budapest, Inst. for Mechanical Technology and Materials Science, H-1111 Budapest, Hungary. 
This report deals with the texture and microstructure development in Ni-coated sheets in comparison to uncoated ones of $\mathrm{Fe}-3 \% \mathrm{Si}$ containing $\mathrm{MnS}$ and $\mathrm{AlN}$ as principal grain growth inhibitors. Both "conventional grain oriented" (CGO) and "highly grain oriented" (HGO) qualities were investigated. Attention is also paid to the state and content of carbon following decarburization and carbide segregation procedures. The main emphasis is put on texture investigations for which the powerful ODF method was used. More detailed metallographic results on grain growth kinetics will be given in a subsequent paper. ${ }^{32}$

\section{EXPERIMENTAL}

\section{Materials and Processing}

As starting material annealed hot bands of different batches of $\mathrm{Fe}-3 \% \mathrm{Si}$ material were used. Their chemical compositions are given in Table 1. Material A and B are of the CGO quality and stem from different charges of the same producer. In this case normal grain growth is mainly inhibited by MnS second phase particles. Materials C and D are of HGO quality and come from two different producers. Here the principal grain growth inhibitors are AlN and MnS. Material E is identical with $\mathrm{D}$ and has only been given a different heat treatment.

Some steps of the processing route are found in Table 2. The annealed hot bands (thickness $2.6 \mathrm{~mm}$ for Materials A, B, and $2.3 \mathrm{~mm}$ for C, D, and E) were cold rolled to $81-86 \%$ reduction on laboratory rolling mills (CR1). For Material $B$ a short intermediate anneal in vaccum at $4 \times 10^{-4} \mathrm{mbar}, 850^{\circ} \mathrm{C}$ for $15 \mathrm{~min}$ and a subsequent second cold rolling (CR2), and for Material E a long time annealing in vaccuum at $4 \times 10^{-4} \mathrm{mbar}, 850^{\circ} \mathrm{C}$ for 17 hours were applied. The latter treatment was made to investigate the role of carbon in solution and in carbide form. The moderate oxygen pressure in the applied vacuum is sufficient to bring down carbon content by $80 \%$, with the residual carbon $(\sim 40-80 \mathrm{wt} . \mathrm{ppm})$ segregating to grain boundaries and, during slow cooling, forming carbides.

Table 1 Chemical composition of the base materials

\begin{tabular}{llllllll}
\hline Material & $C \%$ & $S i \%$ & $M n \%$ & $S \%$ & $P \%$ & $A l \%$ & $N \%$ \\
\hline A = B(CGO) & 0.020 & 3.26 & 0.140 & 0.014 & 0.011 & 0.007 & 0.0080 \\
C (HGO) & 0.052 & 2.99 & 0.082 & 0.025 & 0.007 & 0.025 & 0.0079 \\
D=E(HGO) & 0.044 & 2.94 & 0.070 & 0.027 & $\times$ & 0.025 & 0.0058 \\
\hline
\end{tabular}

Table 2 Processing routes of the base materials

\begin{tabular}{lllccc}
\hline Material & HB-Anneal & $C R 1$ & Anneal & CR2 & $d(\mathrm{~mm})$ \\
\hline A(CGO) & $950^{\circ} \mathrm{C}, 15 \mathrm{~min}$ & $81 \%$ & - & - & 0.480 \\
B(CGO) & $950^{\circ} \mathrm{C}, 15 \mathrm{~min}$ & $81 \%$ & $850^{\circ} \mathrm{C}, \overline{15} \mathrm{~min}$ & $59 \%$ & 0.200 \\
C(HGO) & $\times$ & $80 \%$ & - & - & 0.465 \\
D(HGO) & $1100^{\circ} \mathrm{C}, 15 \mathrm{~min}$ & $86 \%$ & - & - & 0.300 \\
E(HGO) & $1100^{\circ} \mathrm{C}, 15 \mathrm{~min}$ & $86 \%$ & $850^{\circ} \mathrm{C}, \overline{17} \mathrm{~h}$ & - & 0.300 \\
\hline
\end{tabular}


Table 3 Overview of final annealing experiments including texture results. ([G]=Goss texture; $\langle\gamma\rangle=\langle\gamma\rangle$ fibre texture, $\langle 111\rangle \| \mathrm{ND})$

\begin{tabular}{|c|c|c|c|c|c|c|c|c|}
\hline & UNCO & $A T E D M A T$ & $E R I A L S$ & & NI COATEL & D MATE & ERIALS & \\
\hline$T\left[C^{\circ}\right]$ & $\begin{array}{l}20^{\circ} \mathrm{C} / \mathrm{h} \\
(S L)\end{array}$ & $\begin{array}{l}400^{\circ} \mathrm{C} / \mathrm{h} \\
(\mathrm{SR})\end{array}$ & $\begin{array}{l}3000^{\circ} \mathrm{C} / \mathrm{h} \\
(R)\end{array}$ & $\begin{array}{l}12,000^{\circ} \mathrm{C} / \mathrm{h} \\
(E R)\end{array}$ & $\begin{array}{l}20^{\circ} \mathrm{C} / \mathrm{h} \\
(S L)\end{array}$ & $\begin{array}{l}400^{\circ} \mathrm{C} / \mathrm{h} \\
(S R)\end{array}$ & $\begin{array}{l}3000^{\circ} \mathrm{C} / \mathrm{h} \\
(R)\end{array}$ & $\begin{array}{l}12,000^{\circ} \mathrm{C} / \mathrm{h} \\
(E R)\end{array}$ \\
\hline 950 & & & & & & & & \\
\hline & & $\mathrm{A}\langle\gamma\rangle+[\mathrm{G}]$ & $\mathbf{A}\langle\gamma\rangle$ & & & & & \\
\hline & & $\begin{array}{l}\mathrm{B}\langle\gamma\rangle \\
\mathrm{D}\langle\gamma\rangle\end{array}$ & $\begin{array}{l}\mathrm{B}\langle\gamma\rangle \\
\mathrm{D}\langle\gamma\rangle\end{array}$ & $\mathrm{D}\langle\gamma\rangle$ & & $\mathrm{D}[\mathrm{G}]$ & $\mathrm{D}[\mathrm{G}]$ & $\mathrm{D}[\mathrm{G}]$ \\
\hline 1000 & & & & & & & & \\
\hline & & $\begin{array}{l}\mathrm{A}\langle\gamma\rangle \\
\mathrm{B}\langle\gamma\rangle \\
\mathrm{D}[\mathbf{G}]\end{array}$ & $\begin{array}{l}\mathrm{A}\langle\gamma\rangle+[\mathrm{G}] \\
\mathrm{B}\langle\gamma\rangle+[\mathrm{G}] \\
\mathrm{D}[\mathrm{G}]\end{array}$ & & & & & \\
\hline 1050 & & & & & & & & \\
\hline & & $\mathrm{A}\langle\gamma\rangle+[\mathrm{G}]$ & $\mathrm{A} \backslash \gamma\rangle+[\mathrm{G}]$ & $\mathbf{A}\langle\gamma\rangle+[\mathbf{G}]$ & $\mathbf{A}[\mathbf{G}]$ & & $\mathrm{A}[\mathrm{G}]+\langle\gamma\rangle$ & \\
\hline & $\begin{array}{l}B\langle\gamma\rangle \\
D\langle\gamma\rangle\end{array}$ & $\begin{array}{l}B\langle\gamma\rangle \\
D[G]\end{array}$ & $\begin{array}{l}\mathrm{B}\langle\boldsymbol{\gamma}\rangle+[\mathbf{G}] \\
\mathrm{D}[\mathbf{G}] \\
\mathrm{E}\langle\gamma\rangle\end{array}$ & $\mathbf{B}\langle\gamma\rangle+[\mathbf{G}]$ & $\mathrm{D}\langle\gamma\rangle+[\mathrm{G}]$ & $\mathrm{D}[\mathrm{G}]$ & $\begin{array}{l}\mathrm{B}\langle\gamma\rangle \\
\mathrm{D}[\mathrm{G}]\end{array}$ & \\
\hline 1100 & & & & & & & & \\
\hline & $\mathbf{A}[\mathbf{G}]$ & $\mathbf{A}\langle\gamma\rangle$ & $\mathbf{A}\langle\gamma\rangle+[\mathbf{G}]$ & & $\mathrm{A}[\mathrm{G}]$ & & $\mathbf{A}[\mathbf{G}]+\langle\gamma\rangle$ & \\
\hline & $\mathrm{D}\langle\gamma\rangle$ & $\mathrm{D}[\mathrm{G}]$ & $\begin{array}{l}\mathrm{D}\langle\gamma\rangle \\
\mathrm{C}\langle\gamma\rangle \\
\mathrm{D}[\mathrm{G}] \\
\mathrm{E}\langle\gamma\rangle\end{array}$ & & $\mathrm{D}\langle\gamma\rangle+[\mathrm{G}]$ & $\mathrm{D}[\mathrm{G}]$ & $\begin{array}{l}\mathrm{C}[\mathrm{G}] \\
\mathrm{D}[\mathrm{G}]\end{array}$ & \\
\hline
\end{tabular}

After these treatments the sheets now having their final thickness $(d=0.2$ to $0.48 \mathrm{~mm}$ ) were either directly high temperature annealed or first electrochemically coated $(25 \mu \mathrm{m} \mathrm{Ni} \text { on both sides, see also })^{21}$ and then annealed. Both types of experiments are presented in Table III. For the annealing experiments several holding temperatures and heat-up rates were used $\left(T=950^{\circ} \mathrm{C}, 1000^{\circ} \mathrm{C}, 1050^{\circ} \mathrm{C}\right.$, $1100^{\circ} \mathrm{C}$, and $d T / d t=20,400,3000,12,000^{\circ} \mathrm{C} / \mathrm{h}$, the latter in the following referred to as slow (SL), semi-rapid (SR), rapid (R), extremely rapid (ER)). The heat treating atmosphere (vacuum at $p=4 \times 10^{-4} \mathrm{mbar}$ ), the holding time ( $\tau=4$ hours and cooling rate $\left(-100^{\circ} \mathrm{C} / \mathrm{h}\right)$ were kept constant. It needs to be mentioned that, for checking reproducibility, often the experiments were repeated, in cases of very unexpected (i.e. "interesting") results even 5 or 10 times (e.g. for Material $\mathrm{A}$ at $1100^{\circ} \mathrm{C}$ and slow heat-up).

\section{Methods and Investigation}

Microstructures for all samples were investigated in the plane of the sheet by grinding and mechanically polishing samples down to mid-thickness to a final $1 \mu \mathrm{m}$ grit followed by etching in $5 \%$ nital solution. These samples were first examined by light microscopy, while the average grain size was determined by the linear intersection method. The same samples with polished and etched surfaces were also used for measuring $\{110\},\{200\},\{112\}$ and $\{013\}$ incomplete pole figures in the $\alpha=5^{\circ}$ to $85^{\circ}$ range using $\mathrm{MoK} \alpha_{1}$ (Zr-filtered) radiation. Measurements were made by a computer controlled texture goniometer installed in the laboratory of the Institute für Allgemeine Metallkunde (RWTH Aachen). ${ }^{38}$ 
The textures will here be described in the form of $\{110\}$ experimental pole figures corrected for background and absorption (e.g. Figures. 5a,b) and in the form of orientation density functions (ODFs) $f\left(\varphi_{1}, \Phi, \varphi_{2}\right)$ giving the volume fraction of orientations which here are characterized by the three Euler angles $\varphi_{1}, \Phi, \varphi_{2}$. The ODFs were calculated by means of series expansion method up to $1=22 .{ }^{39}$ They will be represented in form of contour lines in $\varphi_{1}=$ constant sections as multiples of the random orientation density through the section $0<\varphi_{1}<\pi / 2 ; 0<\Phi<\pi / 2,0<\varphi_{2}<\pi / 2$ of Euler angular space (e.g. Figure $6 \mathrm{a}, \mathrm{b})$. However, since the textures of bcc metals are largely composed of fibre type components, ${ }^{6}$ it is often useful to represent $f\left(\varphi_{1}, \Phi, \varphi_{2}\right)$ along the fibre axes. Here mainly three fibres need to be considered (e.g. Figs. 7a,b,c) which are named after: ${ }^{6}$

1. $\langle\alpha\rangle$ fibre (Figure 7a), where $\langle 110\rangle \| R D$, from $\Phi=0^{\circ}$ to $\Phi=90^{\circ}$ at $\varphi_{1}=0^{\circ}$ and $\varphi_{2}=45^{\circ}$

2. $\langle\gamma\rangle$ fibre (Figure $7 \mathrm{~b}$ ), whereas $\langle 111\rangle \| N D$, from $\varphi_{1}=0^{\circ}$ to $\varphi_{1}=90^{\circ}$ at $\Phi=55^{\circ}$ and $\varphi_{2}=45^{\circ}$. Due to threefold symmetry along $\varphi_{1}$ the subspace $\varphi_{1}=60^{\circ}$ to $90^{\circ}$ is sufficient for representation.

3. $\langle\eta\rangle$ fibre (Figure 7c), where $\{001\} \| \mathrm{RD}$. This fibre contains the cube $\{001\}\langle 100\rangle$ as well as the Goss orientation $\{011\}\langle 100\rangle$, ranging from $\Phi=0^{\circ}$ to $90^{\circ}$ at $\varphi_{1}=0^{\circ}$ and $\varphi_{2}=0^{\circ}$. Due to a twofold symmetry a $\Phi=0^{\circ}$ to $45^{\circ}$ representation is sufficient.

\section{RESULTS}

\section{Microstructure and Grain Size}

Figure 1, shows a micrograph of a sample of Material A covered with $25 \mu \mathrm{m} \mathrm{Ni}$ slowly heated $\left(20^{\circ} \mathrm{C} / \mathrm{h}\right)$ to be annealed at $1050^{\circ} \mathrm{C}\left(\mathrm{A} / \mathrm{Ni}(\mathrm{SL}) 1050^{\circ} \mathrm{C}\right)$. Zig-zag interfaces between the $\mathrm{Fe}-3 \% \mathrm{Si}$ matrix and the $\mathrm{Ni}$ layers indicate a diffusion of $\mathrm{Ni}$ into the matrix preferentially along the grain boundaries. As an example for microstructures Figures 2a,b give those for Material A without and with $\mathrm{Ni}$ coating annealed at $1050^{\circ} \mathrm{C}$ after semi-rapid (SR) heat up. One recognizes the much larger grains for the $\mathrm{Ni}$ coated Material $\mathrm{A}$. Mean grain sizes of 0.7 and $25 \mathrm{~mm}$, respectively, were found for the two materials. Another example compares the microstructure of Material $\mathrm{D}$ after final heat treatment at $1050^{\circ} \mathrm{C}$ with heat-up rate $(R)$ (Figure 3a) compared to the corresponding one of Material E (Figure $3 b$ ) that, in contrast to $D$, had a 17 hours decarburization anneal at

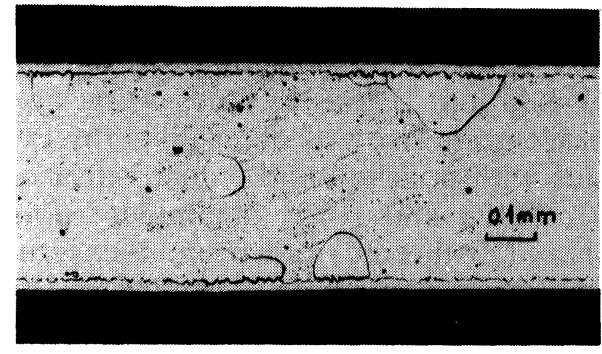

Figure 1 Microstructure of material A/Ni after a final heat treatment (HT) of $1050^{\circ} \mathrm{C}$ with (SL) heat up rate. Side view. 


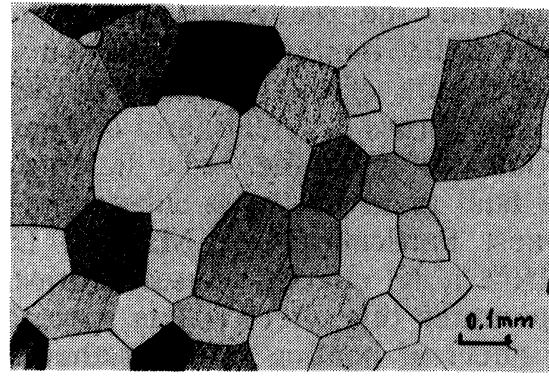

(a)

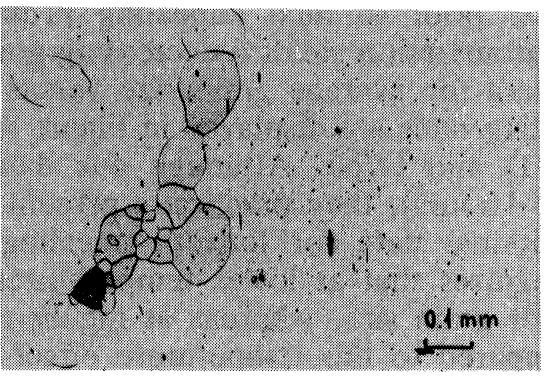

(b)

Figure 2 Microstructure of (a) Material A and (b) Material A/Ni after a final $\mathrm{HT}$ of $1050^{\circ} \mathrm{C}$ with (SR) heat up rate.

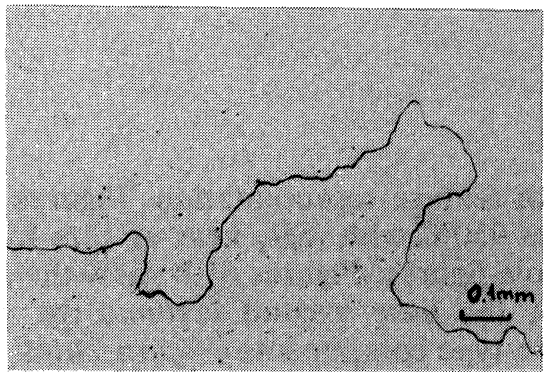

(a)

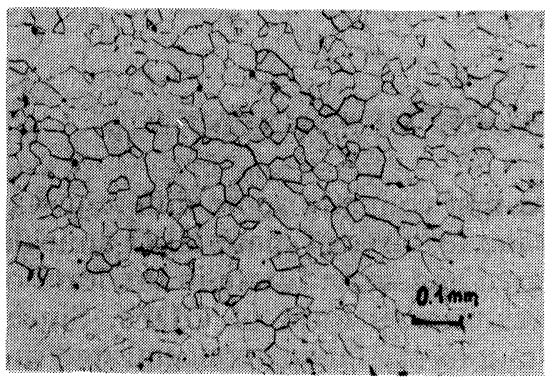

(b)

Figure 3 Microstructures of (a) Material D and (b) Material E after a final HT of $1050^{\circ} \mathrm{C}$ with (R) heat up rate.

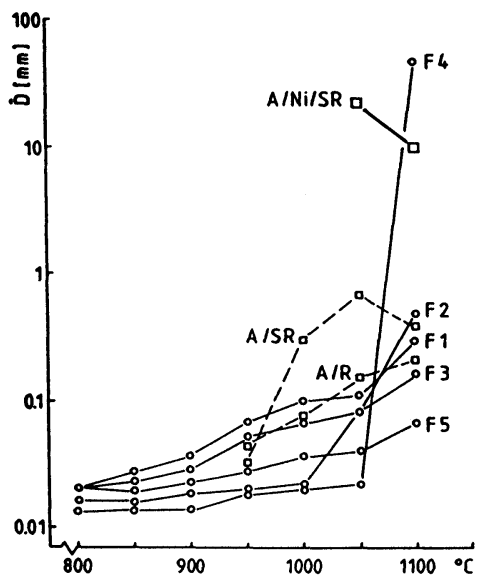

(a)

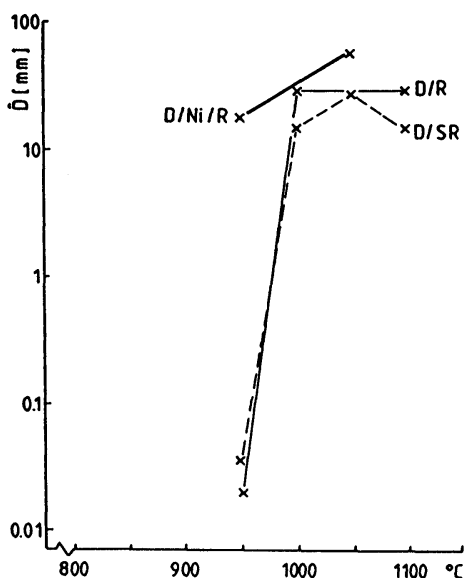

(b)

Figure 4 Grain size versus final HT temperature data for (a) Material A, A/Ni and Fiedler's alloys taken from Ref. 24, (b) Material D and D/Ni. 
$850^{\circ} \mathrm{C}$ prior to final annealing (Table 2) and one recognizes that here the decarburization yields a decreasing grain size $(0.036 \mathrm{~mm}$ compared to $30 \mathrm{~mm})$.

Data for average grain size versus temperature of final anneal for different heating rates are displayed in Figure 4a for Materials A, A/Ni, and in Figure 4b for $\mathrm{D}$ and $\mathrm{D} / \mathrm{Ni}$. Although our data points refer to the same holding time ( $\tau=4$ hours), they practically present the final grain size as is substantiated by additional data for longer annealing times. Particularly for Material D one recognizes that at lower temperatures $\left(950^{\circ} \mathrm{C}\right)$, Ni coating causes a drastically larger grain size, whereas at higher temperaures this effect is less spectacular. Compared to this temperature effect the effect of heating rate is rather small. Also for Material A at lower temperatures a larger grain size for the Ni coated samples compared to the uncoated ones is observed. Also the grain size data found by Fiedler for $\mathrm{B}, \mathrm{N}$, and $\mathrm{S}$ solution-drag inhibited $\mathrm{Fe}-3 \% \mathrm{Si}$ alloys ${ }^{24}$ are inserted into Figure 4a. They show a similarity in behaviour to our Material A. This is indeed remarkable, since, in contrast to Fiedler's alloys, our Material A was chiefly MnS second phase inhibited.

\section{TEXTURE MEASUREMENTS}

Let us first compare some different ways of texture representation. Figures $5 \mathrm{a}, \mathrm{b}$ show the textures of material $\mathrm{D}$ annealed at $950^{\circ} \mathrm{C}$ with (SR) heat-up rate for the uncoated and coated state in the form of pole figures. Figures $6 a, b$ show the same two textures in form of ODFs. Since for the here treated textures the grain orientations are largely concentrated in fibre-type components ("quasi fibres"), in the following - as a third representation method-only the orientation density along the fibre axes will be presented. This representation has the advantage of being very simple but showing quantitatively the essential features of the texture. In Figure 7 the densities along the $\langle\alpha\rangle,\langle\gamma\rangle$, and $\langle\eta\rangle$ fibre (see above) for the two ODFs of Figures $6 a, b$ are plotted (uncoated material empty, coated material full symbols).

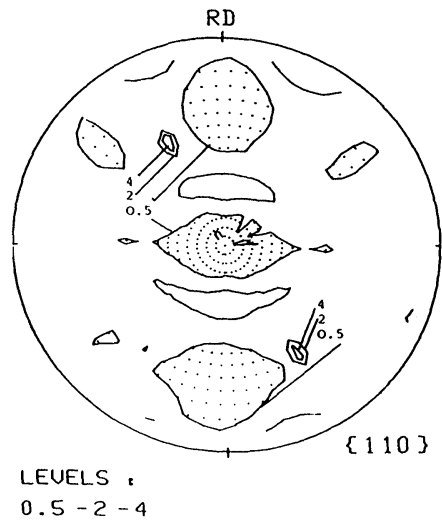

(a)

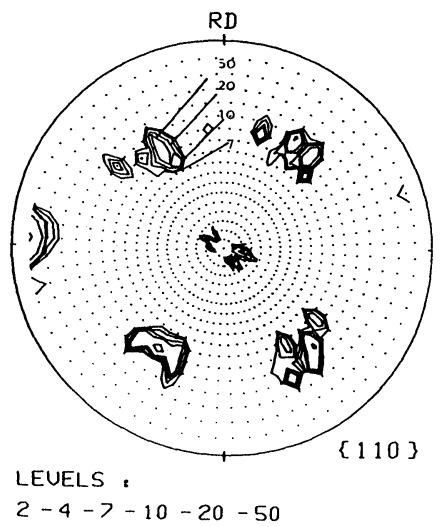

(b)

Figure 5 (110) pole figure of (a) Material D and (b) Material D/Ni after a final $\mathrm{HT}$ at $950^{\circ} \mathrm{C}$ with (SR) heat-up rate. 


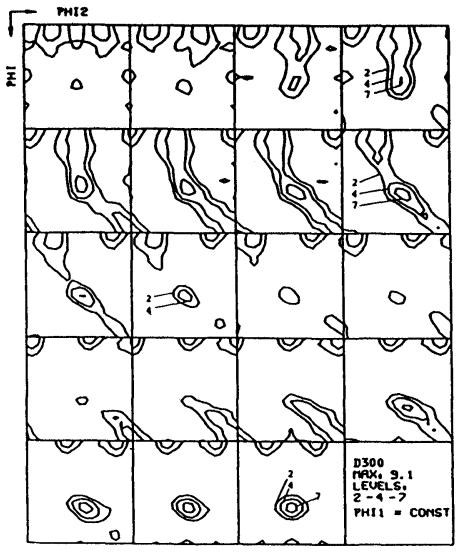

(a)

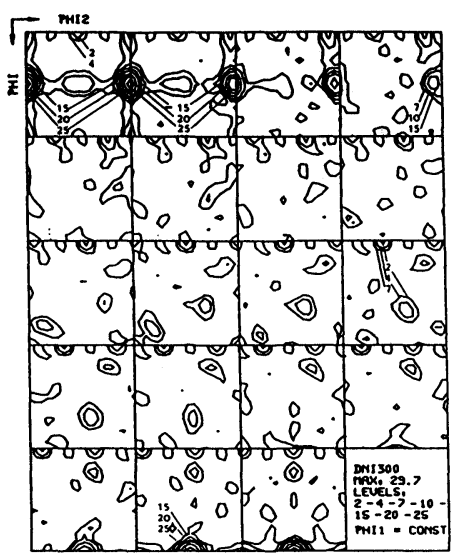

(b)

Figure 6 ODFs of (a) Material D and (b) Material D/Ni after a final $\mathrm{HT}$ at $950^{\circ} \mathrm{C}$ with (SR) heat-up rate.

Considering now the actual textures of Material $\mathrm{D}$ and Material $\mathrm{D} / \mathrm{Ni}$, one recognizes from Figures 5 to 7 that the coated and uncoated material possesses a completely different texture: the Ni coated material displays a sharp Goss texture, whereas the uncoated materials shows a texture rather similar to that found after primary recrystallization, i.e. characterized by a pronounced $\langle\gamma\rangle$ fibre $\langle 111\rangle \| N D$ with a strong $\{111\}\langle 211\rangle$ component (as shown in $^{6}$ or which can be formed by annealing at $850^{\circ} \mathrm{C}$ for $15 \mathrm{~min}$ ). In this case the difference between the two textures is so large that qualitatively it shows up even in the pole figures, but the ODF gives a quantitative description of this difference: Goss orientation

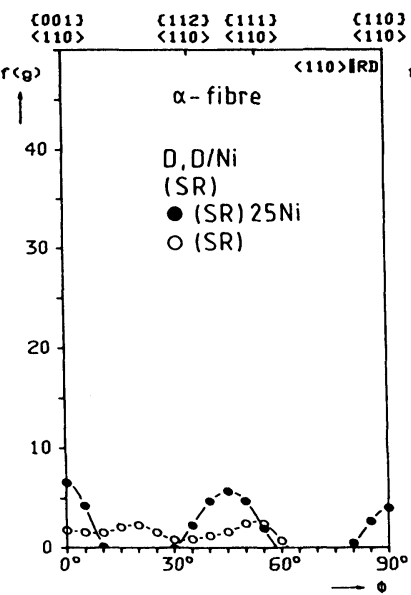

(a)

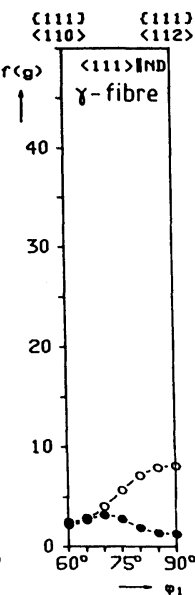

(b)

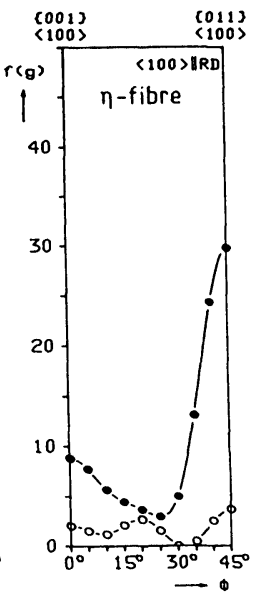

(c)

Figure 7 ODF-fibres of Material D (empty symbols) and Material D/Ni (full symbols) taken from the ODFs shown in Figure 6. (a) $\langle\alpha\rangle$-fibres, (b) $\langle\gamma\rangle$-fibres, (c) $\langle\eta\rangle$-fibres. 
$\{011\}\langle 100\rangle$ possesses an orientation density of 3.6 times random, for the coated material the value 29.7 is found as can also be seen in Figures $7 \mathrm{a}, \mathrm{b}$. There a higher density for the coated material can be recognized also for the Cube orientation $\{001\}\langle 100\rangle(8.8$ to 2.0$)$ situated too in the $\langle\eta\rangle$ fibre, and a lower density for the $\{111\}\langle 211\rangle$ orientation $(1.1$ to 7.8$)$ in the $\langle\gamma\rangle$ fibre.

In Figure 8, similarly, the compact $\langle\alpha\rangle,\langle\gamma\rangle$ and $\langle\eta\rangle$ fibre representation of the ODF is applied to demonstrate the dependence of the textures of Material D (SR), uncoated (empty symbols) and coated (full symbols) on the annealing temperatures. All Ni coated samples show with increasing temperature a steep increase of the $\langle\eta\rangle$ fibre density, particularly near the Goss orientation, and a corresponding decrease of intensities in the $\langle\gamma\rangle$ fibre, particularly near $\{111\}\langle 211\rangle$. It is of special interest that for the coated samples this increase of the Goss orientation density occurs at lower temperature $\left(<950^{\circ} \mathrm{C}\right)$ than for the uncoated samples $\left(\approx 1000^{\circ} \mathrm{C}\right)$ so that the Goss orientation of the coated compared to the uncoated sample is strongly preferred at $950^{\circ} \mathrm{C}$ but of nearly equal magnitude at $1050^{\circ} \mathrm{C}$. The dependence on heat-up rate is presented in Figure 9 for $T=1050^{\circ} \mathrm{C}$. For higher heating rates a pronounced Goss texture is obtained. There are some indications, that for both materials the orientation density at the Goss orientation as function of heating rate runs through a maximum.

The effect of $\mathrm{Ni}$ coating on the development of Goss orientation is confirmed by measurements on Material C, another HGO material. We note in Fig. 10 (annealing at $1100^{\circ} \mathrm{C}$ with (R) heat-up rate) that material $\mathrm{C}$ uncoated gives very little Goss, but coated with 25 or $50 \mu \mathrm{mNi}$ shows a strong increase of this component accompanied by a pronounced drop of the $\langle\gamma\rangle$ fibre components. By enlarging the thickness of the Ni layer from the so far used $25 \mu \mathrm{m}$ to $50 \mu \mathrm{m}$, the effect seems to increase.

Now, for considering the textures of RGO Material, for both uncoated and Ni coated states the three fibres are shown in Figure 11 for Material A (annealed at $1050^{\circ} \mathrm{C}$ with (SL), (R) and (ER) heat up rates) and in Figure 12 for Material B

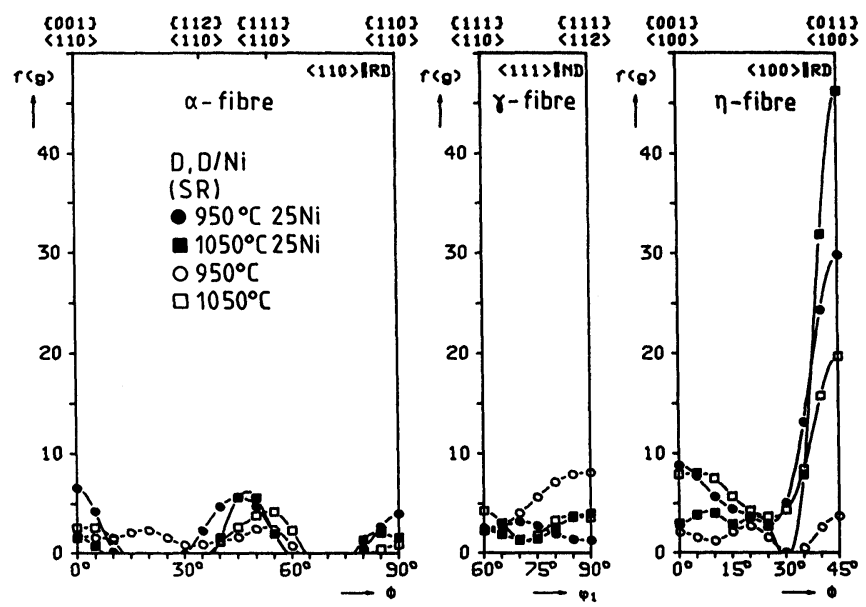

Figure 8 ODF-fibres of Material D (empty symbols) and D/Ni (full symbols) after a final HT of $950^{\circ} \mathrm{C}$ and $1050^{\circ} \mathrm{C}$ with (SR) heat-up rate. 


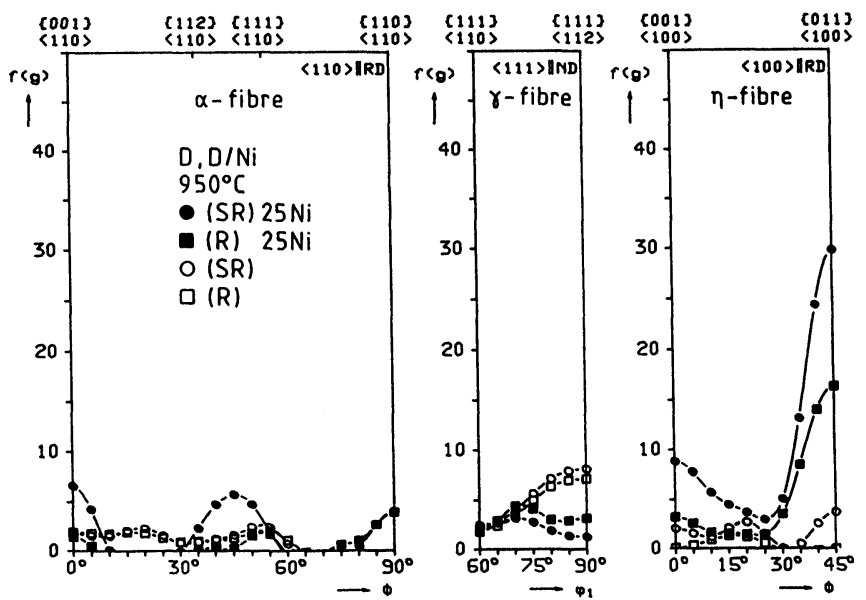

Figure 9 ODF-fibres of Material D (empty symbols) and D/Ni (full symbols) after a final HT of $950^{\circ} \mathrm{C}$ at $(\mathrm{SR})$ and $(\mathrm{R})$ heat-up rate.

(annealed at $1050^{\circ} \mathrm{C}$ with (R) heat up rate). For Material A coating causes clearly an increase of Goss which again is connected with a decrease of $\{111\}\langle 211\rangle$ in the $\langle\gamma\rangle$ fibre. For Material B which possesses a quite high density at $\{111\}\langle 110\rangle$ (which is situated just at the intersection of the $\langle\alpha\rangle$ and $\langle\gamma\rangle$ fibre), but only little Goss, coating did not lead to the formation of a Goss texture, but there is a significant drop of the $\{111\}\langle 110\rangle$ component (28 compared to 7 ), and a build-up of the $\langle\gamma\rangle$ fibre. For this reason Material B, which is chemically the same as Material A, only received an additional anneal at $850^{\circ} \mathrm{C}$ and a second cold rolling (cf. Tables I and II) is unsuitable for use as thin gauge grain oriented steel material.

Finally, the effects of the different concentrations and precipitation states of

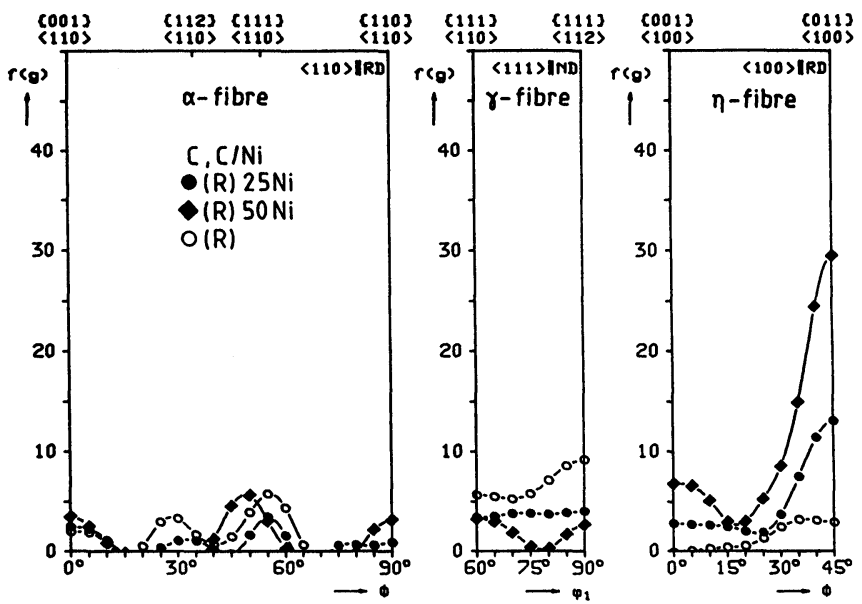

Figure 10 ODF-fibres of Material C (empty symbols) and C/Ni (full symbols) after a final HT of $1100^{\circ} \mathrm{C}$ with (R) heat up rate. 


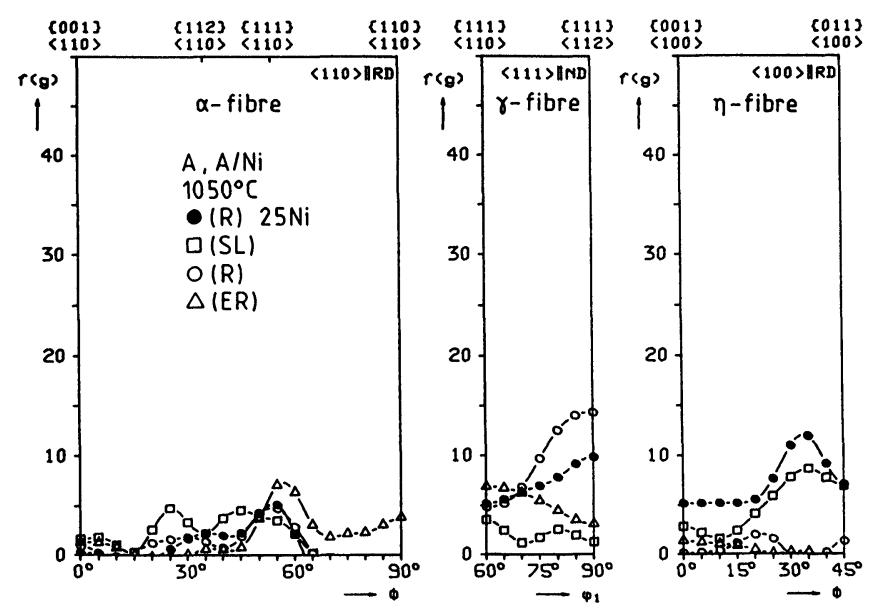

Figure 11 ODF-fibres of Material A (empty symbols) and A/Ni (full symbols) after a final $\mathrm{HT}$ of $1050^{\circ} \mathrm{C}$ with (SL), (R) and (ER) heat up rates.

carbon shall be tested. As an example in Figures 13a,b the textures of the uncoated Materials $D$ and $E$ after a $1050^{\circ} \mathrm{C}$ anneal with (R) heat-up rate are shown in the form of ODFs. It is clearly noted that sample $E$ which after the foregoing long $850^{\circ} \mathrm{C}$ pre-annealing treatment (Table II) had lost most of its carbon displays a texture more typical for primary recrystallization textures, whereas sample D with more carbon left shows a very sharp Goss texture. It should also be mentioned that for material $\mathrm{D}$ when annealed at $1050^{\circ} \mathrm{C}$ only with (SL) instead of (R) heat up rate no Goss was formed either. It is thought that the slow heat up rate already provides enough time for decarburization and for residual carbon to segregate and to form carbides to such an extent that the required inhibition by $\mathrm{C}$ in solution cannot take place.
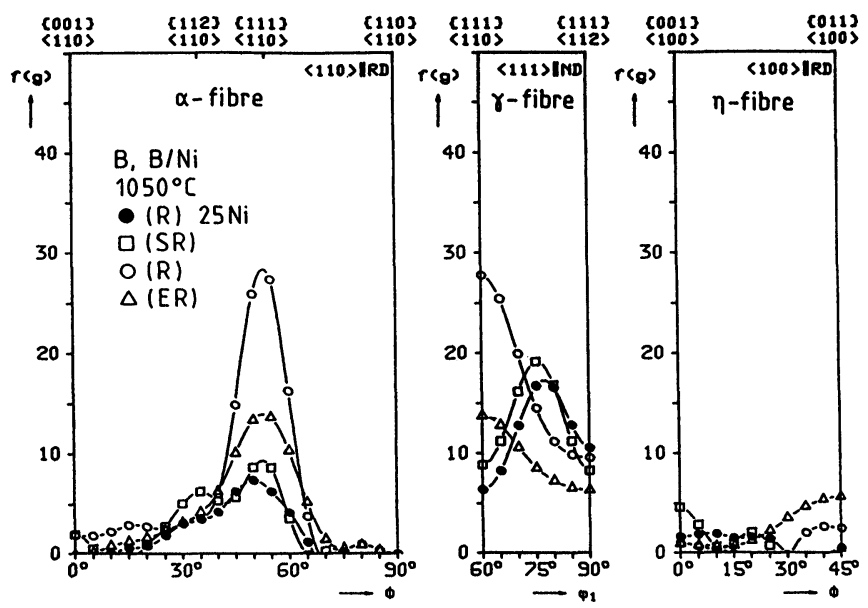

Figure 12 ODF-fibres of Material B (empty symbols) and B/Ni (full symbols) after a final HT of $1050^{\circ} \mathrm{C}$ with (SR), (R) and (ER) heat-up rates. 


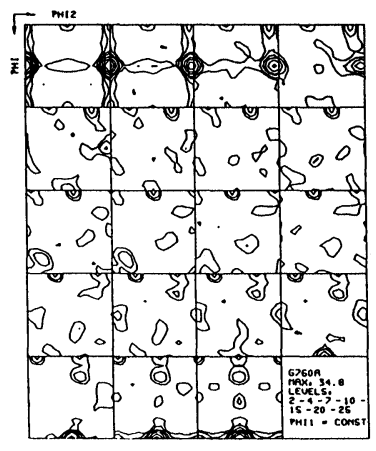

(a)

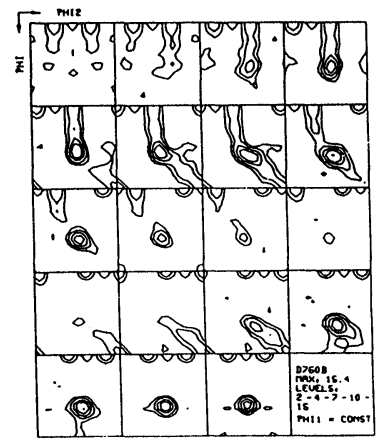

(b)

Figure 13 ODFs of (a) Material D and (b) Material E after a final HT of $1050^{\circ} \mathrm{C}$ with (R) heat up rate.

Table 3 lists in an abbreviated form the most important results. There the textures are classified into 4 groups: $\langle\gamma\rangle$ (very strong $\langle\gamma\rangle$, practically no Goss), $\langle\gamma\rangle+\mathbf{G}(\langle\gamma\rangle$ predominant, some Goss), $\mathbf{G}+\langle\gamma\rangle$ (Goss predominant, some $\langle\gamma\rangle$ ), and G (very strong Goss, practically no $\langle\gamma\rangle$ ).

\section{DISCUSSION}

\section{The Effect of Ni Coating}

The most striking result of the present paper is the discovery that by Ni-coating the onset of abnormal grain growth is shifted to lower temperatures. This shows up in both the grain size and texture measurements. E.g. in the HGO Material D the strong increase in grain size (to values of 5 to $30 \mathrm{mmm}$ ) or change in texture (from primary recrystallization texture with strong $\langle\gamma\rangle$ into pronounced Goss texture) with increasing temperature occur at $1000^{\circ} \mathrm{C}$ for the uncoated state (Figures 4b,8), whereas for $\mathrm{Ni}$-coated material these changes were already completed at temperatures $\leqq 950^{\circ} \mathrm{C}$. Similar results were found in the other HGO Material C (Figure 10) and in the RGO Material A (Figure 11). Although the details of the transition still depend on the heating rate it can be stated rather generally that Ni-coating promotes DGG and thus the formation of Goss texture. That this has not been found for Material B (Figure 12) seems to be connected with the carbon content and will be discussed later.

Also at temperatures above the transition temperature DGG seems to be promoted and the Goss texture sharpened by Ni coating (Figures 7, 8, 10,11). However, this dependence on final annealing temperature and also on heat-up rate is not always accurately established yet and will be treated more thoroughly in a subsequent paper. ${ }^{32}$ It is obvious that, because of the large size of the Goss grains (up to $41 \mathrm{~mm}$ ), here the true statistics is only incompletely fulfilled so that a certain irreproducibility of final grain size and texture will occur.

The reason for the effect of $\mathrm{Ni}$ coating is not completely understood yet. There seems to be two principal possibilities:

(i) It is a true surface effect in the sense that the surface energies e.g. of the 
Goss grains with respect to the Ni layer are more favourable for growth of these grains than for growth of grains of different orientations. This would be a process similar to the so-called tertiary recrystallization where the growth preference of differently oriented grains is changed by a different annealing atmosphere. ${ }^{30}$

(ii) It is a bulk effect in the sense that $\mathrm{Ni}$ is diffusing into the grain boundaries of the sample and is thus affecting the grain boundary behaviour also in the interior of the sample. The occurrence of such a relatively rapid grain boundary diffusion of $\mathrm{Ni}$ into the $\mathrm{Fe}-3 \% \mathrm{Si}$ base material was shown as early as 1953 by autoradiographic studies, ${ }^{29}$ and recently even the grain boundary diffusion coefficients for $\mathrm{Fe}$ and $\mathrm{Ni}$ into $\mathrm{Fe}$-based alloys were measured. ${ }^{23}$ The enrichment of the grain boundaries with $\mathrm{Ni}$ in the bulk of our samples shows up in a network of $\mathrm{Ni}$ covered grain boundaries structure, e.g. in Figure 1. For this reason in the following only this possibility (ii) will be considered further.

\section{THE INFLUENCE OF CARBON CONTENT AND STATE}

As shown above for the case that a long decarburization annealing is applied (Material E), no DGG occurs even at a temperature as high as $1050^{\circ} \mathrm{C}$. This is opposed to the behaviour of samples not subjected to long time decarburization (Material D) and can be seen for both grain size and texture measurements. Material $D$ has very large grains $(\approx 30 \mathrm{~mm}$ ) (Figure $3 a)$ and a pronounced Goss texture (Figure 13a) whereas Material $E$ shows a small grain size $(\approx 0.04 \mathrm{~mm}$, Figure $3 b$ ) and a strong $\langle\gamma\rangle$ fibre, especially $\{111\}\langle 211\rangle$ (Figure 13b) which are characteristic for primary recrystallized structures. This experiment indicates that, contrary to common belief, MnS and AlN inhibitors alone are not sufficient to induce DGG. Since by the decarburization treatment carbon is removed from solution-both by diffusing out of the material or by segregation and carbide precipitation of the rest at the boundaries-it is concluded that the inhibition of the grain boundary motion caused by the solution drag of dissolved carbon is essential for the occurrence of DGG.

This is reiterated by Harase's findings 9 that, in order to induce DGG, in addition to the inhibitors of suitable size and spacing being present in the matrix $^{2,27}$ the AlN particles must form a concentration gradient over the sample thickness. Then the smaller concentration near the surface (due to lack of additional AIN formation during annealing in the $\mathrm{H}_{2} / \mathrm{N}_{2}$ atmosphere) already allows growth of grains when in the interior boundary motion is still inhibited. For similar reasons also for carbon a concentration profile and thus nucleation for secondary grains near the surface might be obtained. Since current mill processing of industrial $\mathrm{Fe}-3 \% \mathrm{Si}$ alloys brings carbon content down to $30 \mathrm{wt}$. ppm and gives time for the residual carbon to segregate to grain boundaries and to form carbides there, ${ }^{26}$ DGG can be secured here only by the effect of the AIN concentration profile. ${ }^{9}$ The further promotion of DGG by Ni coating will be discussed below. It should be mentioned that also low heat-up rates may cause a decarburization sufficient for depression of DGG.

\section{THE INTERPLAY OF C, N, S SEGREGATES}

The influence of $\mathrm{Ni}$ on DGG can probably be best understood in terms of competition for favourable segretation sites of third elements as $\mathrm{C}, \mathrm{N}, \mathrm{S}$, and of 
co-segretation of these elements. Now a few examples will be shown. Fiedler et $a .^{24}$ used $\mathrm{B}, \mathrm{N}$, and $\mathrm{S}$ solute segregates to inhibit normal grain growth in $\mathrm{Fe}-3 \%$ $\mathrm{Si}$ with results partly shown in Figure 4a. Auger Electron Spectroscopy (AES) of the grain boundary segregation in these alloys ${ }^{11}$ yielded that the condition for obtaining the largest secondary recrystallized grains is a high $\mathbf{B}$ and low $\mathbf{N}$ segregation and shows that replacing one interstitial atom (B) by another (N) with a slightly different atomic radius may bring a totally different behaviour. Another study on $\mathrm{Fe}-\mathrm{Sb}-\mathrm{C}$ and $\mathrm{Fe}-\mathrm{Sb}-\mathrm{Ni}$ alloys ${ }^{12}$ showed that a high concentration of $\mathrm{C}$ severely impedes, but $\mathrm{Ni}$ strongly promotes $\mathrm{Sb}$ segregation. An AES study on $\mathrm{Fe}-\mathrm{S}-\mathrm{C}$ alloys ${ }^{25}$ revealed a site competition between $\mathrm{S}$ and $\mathrm{C}$, and a microscopic investigation on $\mathrm{Fe}-\mathrm{C}-\mathrm{Ni}$ alloys ${ }^{26}$ showed that $\mathrm{Ni}$ impedes carbide formation at the grain boundaries. This is partly explained by Guttmann's co-segregation model. ${ }^{28}$ Summarizing the addition of $\mathrm{Ni}$ may influence the behaviour of the boundary not only directly by the $\mathrm{Ni}$ atoms present there, but also indirectly by the change of segregation (and also precipitation) of third kinds of atoms due to the presence of $\mathrm{Ni}$ atoms. E.g. the presence of Ni suppresses the segregation of $\mathrm{C}$, but promotes that of $\mathrm{Sb}$, while $\mathrm{C}$ pushes away $\mathrm{S}$ in the boundary.

The detailed application of such considerations for interpretation of the effect of $\mathrm{Ni}$ coating are not quite clear yet. Due to the suppression of the carbon segregation, there will be more sites available at the grain boundaries for $\mathrm{S}$ and $\mathrm{N}$ to segregate. This consequently leads to additional AlN and MnS formation and thus to a change of the DGG characteristics. According to the results of this work these changes must be in the sense of promotion of DGG. On the other hand, the removal of carbon-also from the grain boundaries-by decarburization suppresses DGG. In any case the net outcome must be such that DGG is facilitated. It will then occur particularly near the surface where, due to the short diffusion path, the $\mathrm{Ni}$ concentration is higher so that there large grains will be formed which then can act as nuclei for the grains appearing in DGG. It should be mentioned that possibly also a direct influence of the $\mathrm{Ni}$ atoms exists. If one supposes that the activation energy for grain boundary mobility is made up of similar terms as that for grain boundary diffusion, a higher mobility for the $\mathrm{Ni}$ coated grains should be found. Since the grain boundary diffusivity of $\mathrm{Ni}$ in $\mathrm{Fe}-\mathrm{Ni}$ alloys is larger than that of $\mathrm{Fe}$ at $550^{\circ} \mathrm{C}$ approximately by a factor of 5:

$$
\begin{aligned}
& \mathrm{P}^{\mathrm{Ni}}=23.10^{-16} \mathrm{~cm}^{3} \mathrm{~s}^{-1} . \\
& \mathrm{P}^{\mathrm{Fe}}=5.4 \cdot 10^{-16} \mathrm{~cm}^{3} \mathrm{~s}^{-1} .{ }^{23}
\end{aligned}
$$

\section{Effect of Misorientation}

The mobility of a grain boundary depends on the misorientation of the two neighbouring grains ${ }^{35}$ and is often especially large for high coincidence rate boundaries. ${ }^{34-36} \mathrm{E} . \mathrm{g}$. for $\mathrm{Fe}-3 \% \mathrm{Si}$ bicrystals Ibe and Lücke ${ }^{22}$ observed the highest mobility for the $27^{\circ}\langle 110\rangle$ and $84^{\circ}\langle 110\rangle$ boundaries which are close to the coincidence boundaries $26.5^{\circ}\langle 110\rangle$ with the coincidence rate $\Sigma=19$ and $86.6^{\circ}\langle 110\rangle$ with $\Sigma=17$. Harase ${ }^{8}$ confirmed this idea by showing in HGO quality $\mathrm{Fe}-3 \% \mathrm{Si}$ alloy that the frequency of coincidence boundaries between secondary and primary recrystallization grains is much larger than to be expected in a random case.

In the present work it is observed that in the primary recrystallization texture 
the $\{111\}\langle 211\rangle$ component and in the secondary texture the Goss component is especially strong and that Goss becomes the larger $\{111\}\langle 211\rangle$ component during DGG. This seems to be confirmed by the fact that the orientation relationship between these two orientations is given by $36^{\circ}\langle 110\rangle$ which is only $3^{\circ}$ away from the high coincidence rate boundary $\Sigma=9$ with $38.9^{\circ}\langle 110\rangle$, and thus can be considered as an indication for the effect of oriented growth by motion of high mobility, high coincidence rate boundaries. This high mobility of these boundaries can be explained by both misorientation dependent selective grain boundary segregation or precipitation, i.e. by assuming either that, because of the small interaction of these rather perfectly ordered boundaries with solute atoms, the solute segregation and thus also the solute drag is small, or that, because of the low energy of these boundaries, their interaction with particles and thus also the particle drag is small.

\section{SUMMARY AND CONCLUSIONS}

1. The development of a strong Goss texture by discontinuous grain growth (DGG) in $\mathrm{Fe}-3 \% \mathrm{Si}$ alloys is strongly influenced by thin nickel layers brought onto the surface of the sheets here by electroplating before cold rolling. This can be observed by grain size as well as by texture measurements and occurs in both RGO and HGO materials. These Ni layers generally promote the Goss texture formation, in particular, they may sharpen this texture and decrease the final annealing temperature necessary for its occurrence. They thus represent an additional tool to influence and control the magnetic properties of these alloys.

2. The effect of Ni coating depends on the final annealing temperature and on heating rate. Because of relatively large errors due to the bad statistics over the very large secondary grains these relationships could not always be clearly established.

3. This influence of $\mathrm{Ni}$ coating is caused by diffusion of $\mathrm{Ni}$ along the grain boundaries during the final annealing. In this way a network of interfaces with a Ni-rich alloy composition is formed. However, the properties of the grain boundaries may not be changed only by this difference in the concentration of $\mathrm{Ni}$ atoms, but also by segregations and precipitations of solutes and second phase particles in the boundary which by Auger spectroscopy or microscopy are found to generally be different in the presence of $\mathrm{Ni}$.

4. If the material is decarburized prior to the final annealing instead of DGG and Goss texture formation a small grain size and a texture showing a strong $\langle\gamma\rangle$ fibre with a pronounced $\{111\}\langle 211\rangle$ orientation, i.e. a grain size and texture characteristic for primary recrystallization is obtained. By Ni coating this can be improved only little.

5. The fact that the final secondary recrystallization texture in Ni-plated materials is qualitatively the same as in an unplated material and is only quantitatively modified, suggests that-inspite of the chemically different grain boundaries - the underlying basic mechanisms of secondary recrystallization, i.e. formation and oriented growth of Goss nuclei are essentially the same.

6. Similarly to the final annealing of uncoated materials in a gaseous atmosphere, also by the penetration of $\mathrm{Ni}$ from the surface layer into the grain 
boundaries at final annealing a gradient of properties across the sheet thickness is created. Such a gradient is necessary for allowing faster grain growth in the primary grain structure near the surface so that the forming larger grains can act as nuclei for secondary grains able to grow into the center parts of the sheet.

7. The loading of the grain boundaries in $\mathrm{Fe}-3 \% \mathrm{Si}$ alloys with third elements as $\mathrm{C}, \mathrm{N}, \mathrm{S}$, is controlled by processes like competition for favourable segregation sites and cosegregation which are altered by the addition of Ni. Although some of these processes seem to be already clear (e.g. that $\mathrm{Ni}$ suppresses the $\mathrm{C}$ segregation), their interplay finally leading to the promotion of DGG and the Goss texture is very complicated and not completely understood. It will be discussed in a subsequent paper. ${ }^{32}$

\section{ACKNOWLEDGEMENT}

The authors wish to thank Prof. W. Hu and Dr. M. Hölscher for helpful discussions. One of them (P.G.) expresses his gratitude to the Alexander von Humboldt-Stiftung which by granting a research fellowship for work at the Institute für Allgemeine Metallkunde und Metallphysik in Aachen, made this work possible. The authors are indebted to the Arbeitsgemeinschaft Industrieller Forschungsvereinigungen (AIF) for financial support.

\section{References}

1. Lücke, K., Rixen, R., and Rosenbaum, F. W. (1972). In The nature and behaviour of grain boundaries, ed. H. Hu, Plenum Press, New York, 245-283.

2. Randle, V., Ralph, B. and Hansen, N. (1986). "Grain growth in crystalline materials," Proc. of 7th Riso International Symposium on Metallurgy and Materials Science, eds. N. Hansen, T. Leffers, Riso National Laboratory, Denmark, 123-142.

3. Dasarathy, C. and Hudd, R. C. (1967). Acta metall., 15, 1665-1671.

4. Sakai, T., Matsuo, M., Tanino, M., Shindo, T. and Shiozaki, M. (1981). Proceedings of the 6th International Conference on Textures of Materials, Japanese Institute of Iron and Steel Tokyo, 938-947.

5. Gubernatorov, V. V., Bryshko, N. A. and Sokolov, B. K. (1984). "Origin of secondary recrystallization centres in alloy $\mathrm{Fe}-3 \% \mathrm{Si}$," Phys. Met. Metall., 58, 3, 118-122 (translated from Fiz. metal. metalloved., 58, 3, 542-546 (1981).

6. Mishra, S., Darmann, C. and Lücke, K. (1984). "On the development of the Goss texture in iron-3\% silicon," Acta metall., 32, 2185.

7. Inokuti, Y. C., Maeda, C. and Ho, Y. (1987). Trans. ISIJ 27, 139-144.

8. Harase, J., Shimizu, R. and Watanabe, T. (1986). "The effects of the grain boundary character distribution on grain growth and texture formation in Fe-3\% Si," Proc. 7th Riso Int. Symp. on Metallurgy and Materials Science, ed. by N. Hansen and T. Leffers, Riso National Laboratory, Denmark, 343-349.

9. Harase, J., Shimizu, R., Takashima, K. and Watanabe, T. (1987). "Effect of AIN on the secondary recrystallization of 3\%-Si-Fe alloy," Transactions ISIJ, 27, 965-974.

10. Taguchi, S. and Sakakura, A. (1966). "The effects of AIN on secondary recrystallization textures in cold rolled and annealed (001)[100] single crystals of 3\% silicon iron", Acta metall., 14, 405-423.

11. Rowe, R. G. (1979). "Grain boundary segregation and grain growth inhibition in silicon iron: the effect of boron and nitrogen," Met. Trans. A, 10A, 997-1011.

12. Briant, C. L. (1987). "Grain boundary segregation of antimony and nickel in iron," Acta metall. 35, 1, 149-153.

13. Abruzzese, G., and Lücke, K. (1986). "A theory of texture controlled grain growth-I. Derivation and general discussion of the model," Acta metall., 34, 5, 905-914. 
14. Eichelkraut, H., Abruzzese, G. and Lücke, K. (1988). "A theory of texture controlled grain growth-II. Numerical and analytical treatment of grain growth in the presence of two texture components," Acta metall., 36, 1, 55-68.

15. Abbruzzese, G., Lücke, K. and Eichelkraut, H. (1987). "Grain growth in the presence of textures. Theoretical approach and comparison to experiments," Proc. of 8th Int. Conference on Textures of Materials (ICOTOM-8), Santa Fe, (1987) 693-704.

16. Anderson, M. P., Srolovitz, D. J., Crest, G. S. and Sahnij, P. S. (1984). Acta metall., 32, 783-791.

17. Srolovitz, D. H., Anderson, M. P., Sahnij, P. S. and Crest, G. S. (1984). Acta metall., 32, 793-802.

18. Grest, G. S., Srolovitz, D. J. and Anderson, M. P. (1985). Acta metall., 33, 509-520.

19. Srolovitz, D. J., Crest, G. S., Anderson, M. P. (1985). Acta metall., 33, 2223-2247.

20. Thompson, C. V., and Frost, T. (1987). Acta metall., 33, 887-890.

21. Gangli, P. and Lücke, K. (1987). "Texture changes during grain growth of $3 \%$ silicon iron," Proceedings of the 8th International Conference on Textures of Materials (ICOTOM-8), Santa-Fe, (1987) 735-740.

22. Ibe, G., and Lücke, K. (1966). in Recrystallization, Grain Growth and Textures, ed. H. Margolin, Am. Soc. for Metals, Metals Park, Ohio, 434-453 (1966).

23. Gas, P., Poise, S., Bernardini, J. (1986). "Influence of cosegregation on grain boundary diffusion: experimental study in ultra high purity $\mathrm{Fe}-\mathrm{Ni}-\mathrm{Sb}$ solid solutions," Acta metall., 34, 3, 395-403.

24. Fiedler, H. C. (1977). Met. Trans. A, 8A, 1307.

25. Suzuki, S., Tani, S., Abiko, K. and Kimura, H. (1987). "Site competition between sulfur and carbon at the grain boundaries and their effects on the grain boundary cohesion in iron," Met. Trans. A. 18A, 1109-1115.

26. Umemoto, M., Furuhara, T. and Tamura, I. (1986). "Effects of austenitizing temperature on the kinetics of bainite reaction at constant austenite grain size in $\mathrm{Fe}-\mathrm{C}$ and $\mathrm{Fe}-\mathrm{Ni}-\mathrm{C}$ alloys," Acta metall., 34, 11, 2235-2245.

27. Tweed, C. J., Ralph, B. and Hansen, N. (1984). "The pinning by particles of low and high angle grain boundaries during grain growth," Acta metall., 32, 9, 1407-1414.

28. Guttman, M., (1971). Surf. Sci. 53, 213.

29. Gonberg, H. I., (1953). "High resolution autoradiography for the study of grain boundaries in metals," Michigan University.

30. Dunn, C. G., and Walter, J. L. (1966). In Recrystallization, Grain Growth and Textures, Am. Soc. for Metals, ed. H. Margolin, Metals Park, Ohio, 461-520.

31. Bölling, F., and Hastenrath, M. (1986). Thyssen Technische Berichte, 1, 49-68.

32. Gangli, P., and Lücke, $K$. (to be published later).

33. Barrisoni, M., Candiotti, M. (1978). "New High Permeability Grain Oriented Fe-3\% Si steel," IEEE Trans. on Magnetics, vol. MAG-14, 4, 345-349.

34. Aust, K. T., and Rutter, J. W. (1959). Trans. Am. Inst. Min. Engrs, 215, 820.

35. Pumphrey, P. H. (1976). In Grain Boundary Structure and Properties, eds. G. A. Chadwick and D. A. Smith, Academic Press, New York, 139-200.

36. Shvindlerman, L. S., and Straumal, B. B. (1985). Acta metall., 33, 9, 1735-1749.

37. Sutton, A. P. and Baluffi, R. W. (1987). "On geometric criteria for low interfacial energy," Acta metall., 35, 9, 2177-2201.

38. Hirsch, J., Burmeister, G., Hoenen, L., Lücke, K. (1986). Experimental Techniques of Texture Analysis, ed. H. J. Bunge, DGM Informationsgesellschaft, Verlag Oberursel, 63-72.

39. Bunge, H. J. (1969). Mathematische Methoden der Texturanalyse, Akademie-Verlag Berlin. 